Review Article

\title{
Olive Oil can be a Useful Remedy to Prevent Osteoporosis
}

\author{
Shahnai Basharat, Syed Amir Gilani, Muhammad Mustafa Qamar, Muhammad Ali, Benazir \\ Basharat, Mian Anjum Murtaza
}

\begin{abstract}
Osteoporosis is the major public health issue worldwide. It is the most common bone porosity, especially in women, in which elder people are more susceptible to skeletal delicacy and fracture and is caused when the skeletal mass and microarchitecture degrades with aging. Age, deficient bone growth, early menopause, and oxidative stress are the factors associated with the possible incidence of osteoporosis. Approximately $\mathbf{7 0}$ million people around the world have gotten affected by this disease. Olives and olive oil have a global recognition as a healthy food and the reason is the phenolic components present in it. The benefits of olives and olive oil included; anti-inflammatory properties and reduces oxidative stress. Oleuropein, hydroxytyrosol, and tyrosol prevent the development of multinucleated osteoclasts. Oleuropein intake has beneficial effects against bone loss that are linked with osteoporosis and aging because oleuropein works by increasing the generation of osteoblasts and by decreasing the development of fat cells. Olive oil can be correlated to a lower occurrence of osteoporosis and correspondingly reduced fracture risk. Mediterranean diet can be helpful in decreasing the incidence of osteoporosis. This review aims to address the role of olive oil in the prevention of osteoporosis.
\end{abstract}

Key Words: Olive Oil, Phenolic Compounds, Bone Health, Osteoporosis.

This article may be cited as: Basharat S, Gilani SA, Qamar MM, Ali M, Basharat B, Murtaza MA. Olive Oil can be a Useful Remedy to Prevent Osteoporosis. J Liaquat Uni Med Health Sci. 2019;18(02):84-9. doi: 10.22442/jlumhs.191820606

\section{INTRODUCTION}

The olive tree has a place with the family Oleaceae. This family has around thirty genera and six hundred species. An Integrated System of Classification of flowering plants, the Olea L. class comprises of in excess of thirty species, which are conveyed all through Europe, Asia, Oceania, and Africa with just Olea europaea L. as the developed species ${ }^{1}$. The olive tree (Olea europaea) is broadly developed for the creation of both oil and table olives and exceptionally noteworthy on account of its financial esteem. Olive and olive oil, a conventional nourishment item with a huge number of long stretches of history are the basic parts of the Mediterranean eating routine ${ }^{2}$.

Aside from oleic corrosive, the specific minor segments present in olive oil, for example, hydrocarbons, tocopherols, greasy alcohols, triterpenic mixes, and polyphenols, some of which are known to be calming, make it the quintessential utilitarian nourishment ${ }^{3}$. Phenolic compounds in olive oil play a significant role in human eating pattern and wellbeing, because these mixes demonstration for beneficial element as cancer prevention agents. The real phenolic mixes present in table olives are tyrosol, hydroxytyrosol, oleanolic corrosive, and oleuropein ${ }^{2}$. Olive oil is the standard fat wellspring of the
Mediterranean eating routine and comprises of high olive oil, fruits and vegetables in $\mathrm{it}^{4}$. Basically Virgin Olive Oil comprises around 36 phenolic 6 blends is the most of the way accountable for the fitness advantages that go with ingestion ${ }^{5}$. Osteoporosis is represented as a major public health issue worldwide and it is the most common bone defects in humans ${ }^{6}$. Osteoporosis or bone permeability is a bone disease in Greeks, affects and distress both men and women worldwide. It is a condition in which elder people are more susceptible to skeletal delicacy and fractures is caused when the skeletal mass and is degraded with aging. The bony tissues present at the end of skeletal maturation and amount of loss of bone is regulated by bone density measures grams of mineral per area or volume. The occurrence of osteoporosis, osteoporosis -related fractures, and related obstacles, is defined as intermediate risk group that is called low bone density (osteopenia) ${ }^{7}$.

"Bone remodeling" is a process of both the renewal and repair of bone tissue. Bone tissue has two types of bone cells that are included in bone remodeling. Osteoblasts form the bone and osteoclasts are the processes of reabsorption of bone. The organization of osteoblasts and osteoclasts are inferred from bone homeostasis. The two main reasons for osteoporosis is either the formation of bone or too much absorption. 
The decreased bone mass and then bone strength is caused by the increased incidence of osteoclast reabsorption or decreased ability of osteoblasts ${ }^{8}$.

Over age 65 years irresistible factors are race, sex, genetic factors, familial predilection, deficient bone growth, preceding fractures, oxidative stress, diseases, early menopause, medications ${ }^{9}$. Smoking is connected by increased risk of fracture fracture, and reduce absorption of calcium in intestines and elevate metabolism of endogenous and exogenous estrogens to inactive derivatives ${ }^{10}$.

According to statistics from the International Osteoporosis Foundation (IOF), approximately 200 million women worldwide affected by osteoporosis and it causes 8.9 million fractures every year ${ }^{11}$. A study of Pakistan's population, it has been estimated that the prevalence of this disease is high with nine point ninety million patients and this ratio is expected to get more high in coming years and expecting to become eleven point three million and even more high like twelve point ninety-one million in coming 30 years ${ }^{12}$. The Mediterranean food abundant in fruits, vegetables, and olive oil reduced the prevalence of bone diseases and diminished the rate of bone cracks. The complete phenolic extracts of extra virgin olive oil and the characteristics of effective components of olive oil on hormone replacement of bone loss were confined and its consequence on the reduction of osteoporosis was inspected in previous studies $^{13}$.In many countries who consume the diet which is higher in fruits and vegetables and healthy oils, the prevalence of bone cracks is minor. Extra virgin olive oil is the main component of the Mediterranean food that showed many useful consequences on body and heart strength and lowers the chance of bone cracks ${ }^{14}$.

In the preservation of cartilage fitness, olive oil elements like oleuropein and hydroxytyrosol may have vital consequences. Glycosylatedseco-iridoid (oleuropein) has defensive consequences in bone loss. Oral absorption of an olive petal juice affluent in oleuropein has consequences on the antioxidant position of hormone replacement of females ${ }^{15}$. The oleuropein not only lowers the osteoporosis but also inhibit imbalance between free radicals and antioxidants in the body and prevent infections in the inner layer of the uterus. The oleuropein can prevent bone loss in cancer patients by reducing human epidermal growth receptor 2, gene transformation and exhilarating, which is an adequate method to treat bone loss ${ }^{16}$.

The major phenolic compound in olives and olive oil is Oleuropein with the amount ranging between $1 \mathrm{ppb}$ and $11 \mathrm{ppm}$. Oleuropein improves bone health by increasing the formation of osteoblasts and decreasing the formation of fat cells showing that oleuropein intake might have beneficial effects against bone loss that are linked with osteoporosis and aging. The phenolic compounds in olives also help to regulate transcription factors, increase proliferation capacity, calcium ion removal, and alkaline phosphates activity ${ }^{17}$.

\section{Mechanism}

The two main reasons for osteoporosis is either the formation of bone or too much absorption. Lerner et al said that decreased bone mass and the bone strength is caused by increased incidence of osteoclasts reabsorption or decreased ability of osteoblasts. ${ }^{8}$

Mediterranean diet decreases the occurrence of fractures when given to a person because olive oil is the main part of this diet. The active constituents of extra virgin olive oil, which is obtained from olive oil, are called phenolic compounds. ${ }^{18}$ The strongest antioxidant effect is in hydroxytyrosol, which is a polyphenol of olive oil. It is shown in the flowchart that the ramification of the cells that secrete the bone substance, encompassing their propagated potential, and the extracellular matrix, in which evolvement by deposit of calcium ion happens.

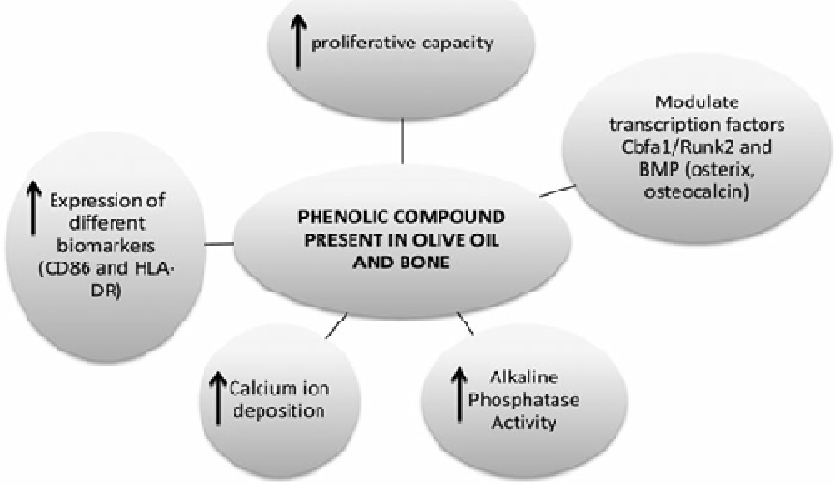

Due to oxidative stress, the bone metabolism is reported to be subdued by an elevation in levels

of oxygen receptive species within the cell. $\mathrm{H} 2 \mathrm{O} 2$ is also decreased by hydroxytyrosol in the osteoblastic cells. Phenolic compounds in olives help to modulate transcription factors and bone morphogenic proteins ergosterol and osteocalcin causes the modification of osteoblast, increase proliferation capacity, expression of different biomarkers which enhance bone mineral density, deposition of calcium in bones and alkaline phosphatase activity.

The essential phenolic compound named oleuropein is found in olive tree leaves, olive oil, and olives. Oleuropein intake has preventive effects against the bone loss associated with bone loss and aging because oleuropein was found to intensify bone health achieved through bone marrow stem cells, where the formation of osteoblasts is elevated and by 
decreasing the development of adipocytes or fat cells. There is an increase in cell proliferation in all tested concentrations by luteolin and apigenin, which are the flavonoids present in olive oil. Flavonoids also elevate the reabsorption action of the bone of extricated osteoclast ${ }^{17}$.

In 2016, a study analyzed the consequences of recurrent intake of olive oil and its change on the revelation of bone linked cracks in people belonging to different age groups. Total 870 people taken from Spain, where persons were $55-80$ years old. The subjects were given $50 \mathrm{~g}$ or more per day of a diet called Mediterranean diet, which was supplemented with extra virgin olive oil and thirty grams of nuts and diet low in fat. Garcia-Gavilan concluded that greater intake of extra virgin olive oil had a minor chance of bone-related fractures in the communities of people belonging to different age groups (elderly and middle-aged $)^{18}$.

In 2014, a study was conducted on postmenopausal women and premenopausal women and both groups received $250 \mathrm{mg}$ of Olive leaf extract (oleuropein). The reason for the experimentation was to investigate the oleuropein impact on disease administration status (osteoporosis) in postmenopausal ladies emerged from premenopausal ladies. The blood samples and urine fractions were collected after specific hours within a 24hperiod. The results exemplified that, in order to intercept the continuance of osteoporosis of bone associated diseases, the postmenopausal women could be the best-aimed population used for the consumption of olive oil (oleuropein) ${ }^{19}$.

In 2015, Sixty women who had stopped getting the menstrual cycle, there was a controlled one-year angle blind randomized case organized on them. Those women were separated into 2 parts. There were two groups and one was experimental, unrefined olive oil which had some of the components like one of $\mathrm{K}$ vitamin, one of the $\mathrm{D}$ vitamins and one of the $\mathrm{B} 6$ vitamin group and this oil was given as supplements in the amount of twenty milliliters every day and the purpose was to look over bone turnover and what was influence on that made oxidative stress. And the conclusions showed that unrefined olive oil which was given to the group who was under experimentation could decrease carboxylate and undercarboxylated BGLAP in supplemented subject comparing to a group that was supposed to be controlled. It might be prescribed that unrefined olive oil that was used with vitamins in eating regime of years after menopause, for protection of bone and procedures against the reduction of oxidative stress in women ${ }^{20}$.

There was a study conducted on some Spanish women by Rauel and his colleagues and in this study, they got to know about when olive oil consumed it had an effect on bone mineral density in the outer layer of the cerebrum and cancellous bone. Almost five twenty -three females with fifty years age were selected. Some laboratory tests were examined which include a test which counts mineral density in bones and peripheral quantitative computed tomography ( $\mathrm{QQCT}$ ). The total density of olive oil detected was $0.185 \mathrm{~g} / \mathrm{day}$, exactly after 2 years follow-up. After all the studies it had been proved that olive oil had a great effect on the volumetric bone mineral density ${ }^{21}$.

In a study conducted earlier, researchers were trying to find if there was a link between the microarchitecture of outer layer of the cerebrum and spongy bone. This study included some women about five twentythree aged between twenty-three to eighty-one years. The osteoporotic diagnosis increased in volumetric bone mineral density among groups was investigated. The participants of the study were supposed to be in group arrangement in the state of their olive oil intake above, below or equal to the median consumption of sample $18.23 \mathrm{gram}$ per day. The result of this study showed that the consumption of olive oil linked with the improved density of bone minerals among Spanish women $^{21}$. In another study, unrefined olive oil as a polyphenolic source effects on bone metabolism was carried out by Benetou and his colleagues. Four groups went into surgery of ovary removal and from with two were sham-operated and theses groups were given food which was ten percent unrefined and refined. Gene expression and bone mineral density both were assessed after the exposure of thirty days. Some data that was available and old showed that weakened bone mass was because of the removal of ovaries and it was also related to bone turnover. Unrefined olive oil if fortified with D3 vitamin then it could protect bone from reshaping and also lower oxidative stress markers. This study got a complete result which showed that fortification of virgin oil with D3 vitamin had a protective effect as a polyphenols source on the metabolism of bone by improving inflammation and oxidative stress ${ }^{22}$. A study conducted in 2014, in which the main function of olive oil on post-menopausal osteoporosis explored. Olive oil active component, additional virgin olive oil add up to polyphenolic portion was secluded and its impact in the counteractive action of osteoporosis was contemplated. Female rodents were ovariectomized and gave them an enhanced aggregate phenolic concentrate of additional virgin olive oil of $800 \mathrm{mg} / \mathrm{kg}$ diet for 12 weeks. In result oleocanthal, a polyphenolic compound showed high estrogen receptor binding. This binding affinity is high with Estrogena as compared to Estrogen $\beta$. It is concluded that when extra virgin olive oil polyphenol is administered, it managed uterine estrogen reaction hereditary 
indicator in a combative way. And the consequence was no bone thrashing by the treatment with polyphenolic extract ${ }^{13}$.

A double-blind placebo control investigation was directed to discover the effect of olive polyphenol separate on serum osteocalcin levels and bone mineral thickness in the lumbar backbone. The sixtyfour participants with mean bone mass (osteopenic) and 1.5 to 2.5 Tscore in the lumbar spine/lower back were incorporated into the investigation. All these contributors have to intake daily either $250 \mathrm{mg}$ concentrate of olives and 100-milligram calcium (handling group) or 1000 milligram calcium for twelve months. At first, the main target was the evaluation of bone turnover and then secondly bone mass density. The result showed that after 12 months the participant who received $250 \mathrm{mg}$ olive extract with $100 \mathrm{mg}$ calcium significantly increase the level of pro-osteoblastic marker osteocalcin as compared to those who received $1000 \mathrm{mg}$ calcium. Bone mass density decreased in the participant who received only $1000 \mathrm{mg}$ calcium while it remains the same in another group who received $250 \mathrm{mg}$ olive and $1000 \mathrm{mg}$ calcium. The results showed that those who were taking the $250 \mathrm{mg}$ olive extract and $1000 \mathrm{mg}$ calcium was effective for serum osteocalcin levels and moreover it stable body mass density (BMD) in lumbar spine $^{23}$.

In 2014, it was studied the impact of olive oil is effective against osteoporosis and inflammation. In this study one hundred and twenty (120) participants examined. Every one of the rodents was separated into four groups. Two groups were given by oral gavage. The dose of extra virgin oil was $1 \mathrm{~mL}$ per $100 \mathrm{~g}$ weight. This dose was given on daily basis for 12 weeks regularly. The alkaline phosphatase, phosphorus, interleukin-6, Malonic aldehyde, and nitrate content was also checked by blood samples. An instrument named as Double vitality X-beam absorptiometer was utilized to quantify the bone mineral thickness of the gatherings that were fed olive oil for three months. The study findings showed that extra virgin olive oil enhanced the bone mineral density and reduced the phosphatase, interleukin-6, and levels of nitrate ${ }^{24}$.

In the previous studies, examined the extra virgin olive oil had anti-osteoporosis effects in vivo Dawley rats. One hundred and twenty female Dawley rats have

\begin{tabular}{|c|c|c|c|c|}
\hline Dietary Treatment & Subject & Duration & Effect on Bone Health & Reference \\
\hline $\begin{array}{c}\text { Extra virgin olive oil }=50 \mathrm{~g} \\
\text { Nuts }=30 \mathrm{~g} \\
\text { Fat }=\text { low amount }\end{array}$ & $\begin{array}{l}870 \text { (Elderly age } \\
55-80)\end{array}$ & $\begin{array}{l}\text { Years } \\
\text { follow up }\end{array}$ & $\begin{array}{l}\text { Minor chance of bone-related } \\
\text { fractures }\end{array}$ & $\begin{array}{l}\text { Garcia-Gavilan J et al., } \\
\text { (2016) }\end{array}$ \\
\hline $\begin{array}{l}\text { Olive leaf extract }= \\
250 \mathrm{mg}\end{array}$ & $\begin{array}{l}\text { Pre and postmeno- } \\
\text { pausal women }\end{array}$ & 24 hour & Help in prevent osteoporosis. & Garcia-Villalba $\mathrm{R}^{19}(2014)$ \\
\hline Virgin olive oil=20ml/day & $\begin{array}{l}60 \text { Caucasian post- } \\
\text { menopausal women }\end{array}$ & 12 months & Bone protection by homeostasis & $\begin{array}{l}\text { Mazzanti L } \\
\text { et al., }{ }^{20}(2015)\end{array}$ \\
\hline Olive oil=0.186/day & $\begin{array}{c}523 \text { (females of } 50 \\
\text { years old) }\end{array}$ & $\begin{array}{l}2 \text { years } \\
\text { follow up }\end{array}$ & Improved Bone mineral density & $\begin{array}{l}\text { Roncero-Martín R et } \\
\text { al., }{ }^{21}(2018)\end{array}$ \\
\hline Olive oil=18.32/day & $\begin{array}{c}523 \text { (females of } 30 \\
\text { years old) }\end{array}$ & Daily & $\begin{array}{l}\text { Improved volumetric bone } \\
\text { mineral density }\end{array}$ & $\begin{array}{l}\text { Roncero-Martín R et } \\
\text { al., }{ }^{21}(2018)\end{array}$ \\
\hline $\begin{array}{l}\text { Extra virgin olive oil with } \\
\text { vitamin } \mathrm{D} 3=5000 \mathrm{IU} / \mathrm{kg}\end{array}$ & 4 Groups of mice & 30 days & $\begin{array}{l}\text { Prevent Bone remodeling. } \\
\text { Lowered expression of oxidative } \\
\text { stress markers. }\end{array}$ & Benetou V et al., ${ }^{22}$ (2013) \\
\hline $\begin{array}{l}\text { Phenolic extract of extra } \\
\text { virgin olive oil= } 800 \mathrm{mg} / \mathrm{kg}\end{array}$ & $\begin{array}{l}\text { Overiectomized female } \\
\text { rats (Above } 12 \text { months) }\end{array}$ & 12 weeks & No bone loss & Keiler MA et al., ${ }^{13}(2014)$ \\
\hline $\begin{array}{l}\text { Olive oil }=250 \mathrm{mg} \\
\text { Calcium }=100 \mathrm{mg}\end{array}$ & participant & 12 months & $\begin{array}{l}\text { Serum osteocalcin increase. } \\
\text { Bone mass density stable in the } \\
\text { lumbar spine. } \\
\text { Blood lipid profile increase with } \\
\text { low cholesterol. }\end{array}$ & Flip R et al., ${ }^{23}$ (2015) \\
\hline $\begin{array}{c}\text { Olive oil=1 Ml/100g } \\
\text { weight }\end{array}$ & $\begin{array}{l}120 \text { (Rats aged } 6 \\
\text { months) }\end{array}$ & 12 weeks & $\begin{array}{l}\text { Bone mineral increased. } \\
\text { Phosphatase, alkaline } \\
\text { phosphatase, interleukin-6, and } \\
\text { nitrate decreased. }\end{array}$ & Huilanliu et al., ${ }^{24}(2014)$ \\
\hline $\begin{array}{l}\text { Extra virgin olive oil=1 } \\
\text { Ml/100g }\end{array}$ & $\begin{array}{l}120 \text { female rats ( } 6 \\
\text { months) }\end{array}$ & 12 weeks & Prevent osteoporosis risk & Lyman GH et al., ${ }^{15}(2014)$ \\
\hline
\end{tabular}


selected there age was of six months. These groups were given extra virgin olive oil then fed with olives and the last group was fed with additional virgin olive oil and estrogen. The dose of extra virgin olive oil and estrogen was $1 \mathrm{~mL} / 100 \mathrm{~g}$ according to their weight for the following twelve weeks. Their bone mineral density was also examined. From the results, it was proved that the additional virgin olive oil had a very important role as anti-osteoporosis ${ }^{15}$. Similarly, a few more studies support the role of extra virgin olive oil in the prevention of osteoporosis by improving the bone health ${ }^{25-27}$

\section{CONCLUSION}

Olive oil enhances the calcium deposition and bone mineral density. Furthermore, the bioactive component of olive oil name oleuropein is of great importance. A trending diet Mediterranean diet includes olive oil which is beneficial in the protection of chronic diseases, especially of bone health.

\section{REFERENCES}

1. Fujiwara $\mathrm{Y}$, Tsukahara $\mathrm{C}$, Ikeda $\mathrm{N}$, Sone Y, Ishikawa T, Ichi I, et al. Oleuropein improves insulin resistance in skeletal muscle by promoting the translocation of GLUT4. J Clin Biochem Nutr. 2017; 61(3): 196-202. doi: 10.3164/jcbn.16-120.

2. Uylaşer V, Yildiz G. The historical development and nutritional importance of olive and olive oil constituted an important part of the Mediterranean diet. Crit Rev Food Sci Nutr. 2014; 54(8): $1092-$ 101. doi: $10.1080 / 10408398.2011 .626874$.

3. Aparicio R, Morales MT, Aparicio-Ruiz R, Tena N, González D. Authenticity of olive oil: Mapping and comparing official methods and promising alternatives. Food Research International.2013; 54(2): 2025-2038. doi: 10.1016/j.foodres.2013.07.039

4. Esturch R, Ros E, Sales-Salvado O, Covas MI, Corella D, Aros F, et al. Primary prevention of cardiovascular disease with a Mediterranean diet. N Engl J Med. 2018; 368(14): 1279-90. doi: 10.1056/NEJMoa1200303.

5. Barbaro B, Toietta G, Maggio R, Arciello M, Tarocchi M, Galli A, et al. Effects of the olive-derived polyphenol on human health. Int $\mathrm{J}$ Mol Sci.2014; 15(10): 18508-24. doi: 10.3390/ ijms151018508.

6. Sozen T, Ozisik L, Başaran NC. An overview and management of osteoporosis. Eur $\mathrm{J}$ Rheumatol. 2017;4(1): 46-56. doi: 10.5152/eurjrheum.2016. 048.

7. Chin KY, Ima-Nirwana S. Olives and Bone: A Green Osteoporosis Prevention Option. Int J Environ Res Public Health. 2016; 13(8): pii E755. doi: 10.3390/ijerph13080755.
8. Jahanian E, Karimifar $M$, Rafieian-Kopaei $M$. Antioxidants as a novel way to alleviate the adverse effects of oxidative stress in osteoporosis. J Parathyr Dis. 2016; 4(2): 60--65.

9. Panday K, Gona, A, Humphrey M. Medication induced osteoporosis: screening and treatment strategies. Ther Adv Musculoskelet Dis. 2014; 6 (5): 185-202.

10. Borissova A-M, Rashkov R, Boyanov M, Shinkov A, Popivanov P, Temelkova N, et al. Risk factors for osteoporosis and 10-year absolute fracture risk in a national representative sample of Bulgarian women aged 50 years and older. Endocrinologya 2011; 16(1): 4-18.

11. International Osteoporosis Foundation. Facts and Statistics. 2018. Available from: https:// www.iofbonehealth.org/facts-statistics.

12. Haris $S$, Jahan F, Afreen A, Ahmed H, Ahmed Z. To determine the risk factors and prevalence of osteoporosis among adult Pakistani population residing in karachi using quantitative ultrasound technique. J Community Med Health Educ. 2014; 4(4): 1-5. doi:10.4172/2161-0711.1000299.

13. Keiler AM, Zierau O, Bernhardt R, Scharnweber $D$, Lemonakis $N$, Termetzi $A$ et al. Impact of a functionalized olive oil extract on the uterus and the bone in a Model of postmenopausal osteoporosis. Eur J Nutr. 2014; 53 (4): 1073-81. doi: 10.1007/s00394-013-0609-4.

14. Savanelli MC, Barrea L, Mocchia P, Savastano S, Falco A, Renzullo A, et al. Preliminiary results demonstrating the impact of Mediterranean diet on bone health. J Transl Med. 2017; 15(1): 81.

15. Lyman GH, Khorana AA, Kuderer NM, Lee AY, Arcelus JI, Balaban EP, et al. Venous thromboembolism prophylaxis and treatment in patients with cancer: American Society of Clinical Oncology clinical practice guideline update. J Clin Oncol. 2013; 31(17): 2189-204. doi: 10.1200/ JCO.2013.49.1118.

16. Valls RM, Farras $M$, Suarez $M$, FernandezCastillejo S, Fito M, Konstantinidou V, et al. Effects of functional olive oil enriched with its own phenolic compounds on endothelial function in hypertensive patients. A randomised controlled trial. Food Chem. 2015; 167:30-35. doi: 10.1016/j. foodchem.2014.06.107.

17. García-Martínez O, De Luna-Bertos E, Ramos-Torrecillas J, Ruiz C, Milia E, Lorenzo ML, et.al. Phenolic compounds in extra virgin olive oil stimulate human osteoblastic cell proliferation. PloS one. 2016; 11(3): e0150045. doi: 10.1371/ journal.pone.0150045.

18. García-Gavilán JF, Bulló $M$, Canudas $S$, Martínez-González MA, Estruch R, Giardina S, 
et al. Extra virgin olive oil consumption reduces the risk of osteoporotic fractures in the PREDIMED trial. Clin Nutr. 2016; 37(1):329-335. doi: 10.1016/j.clnu.2016.12.030.

19. Garcia-Villalba R, Larrosa M, Possemiers S, Tomas-Barberan FA, Espin JC. Bioavailability of phenolics from an oleuropein-rich olive leaf extract and its acute effect on plasma anioxident status: comparison between pre- and postmenopausal women. Eur J Nutr. 2014; 53(4): 1015-1027. doi: 10.1007/s00394-013-0604-9.

20. Mazzanti L, Battino M, Nanetti L, Raffaelli $F$, Alidori A, Sforza G, et al. Effect of 1-year dietary supplementation with vitaminized olive oil on markers of bone turnover and oxidative stress in healthy post-menopausal women. Endocrine. 2015; 50(2): 326-34.

21. Roncero-Martín R, Aliaga V, Moreno-Corral L, Moran J, Lavado-Garcia J, Pedrera-Zamorano J, et al. Olive Oil Consumption and Bone Microarchitecture in Spanish Women. Nutrients. 2018; 10(8): 968. doi: 10.3390/nu10080968

22. Tagliaferri $C$, Davicco MJ, Lebecque $P$, Georgé $S$, Amiot MJ, Mercier $S$. Olive oil and vitamin D synergistically prevent bone loss in mice. Plos One. 2014; 9(12): e115817.

23. Flip R, Possemiers $S$, Heyerick A, Pinheiro I, Raszewski G, Davicco MJ, et al. Twelve month consumption of a polyphenol extract from olive (oleaeuropaea) in a double blind, randomized trial increases serum total asteocalcin levels and improves serum lipid profiles in postmenopausal women with osteopenia. J Nutr Health Aging. 2015;19(1):77-86. doi: 10.1007/s12603-0140480-x.

24. Huilan L, Huijuan $H$, Boheng L, Dong W, Fengmei $W$, Xiao hua $Z$, et al. Olive oil in the prevention and treatment of osteoporosis after artificial menopause. Clin Interv Aging. 2014; 9: 2087-95.

25. Melguizo-Rodríguez L, Ramos-Torrecillas J, Manzano-Moreno F, Illescas-Montes R, Rivas A, Riuz C, et al. Effect of phenolic extracts from different extra-virgin olive oil varieties on osteoblast-like cells. Plos One. 2018; 13(4): e0196530. doi: 10.1371/journal.pone.0196530.

26. García-Martínez O, Rivas A, Ramos-Torrecillas J, De-Luna E, Ruiz C. The effect of olive oil on osteoporosis prevention. Int $\mathrm{J}$ Food Sci Nutr. 2014; 65(7): 834-840. doi: 10.3109/09637486. 2014.931361.

27. Mousavi SN, Koohdani F, Eslaminejad MB, Izadi $P$, Eshraghian $M$, Sayahpour $F A$, et al. Extra virgin olive oil increases osteogenic genes expression, but high amounts have deleterious effect on bones in mice offspring at adolescence. Iran J Basic Med Sci. 2016;19(12):1299-1307.
AUTHOR AFFILIATION:

\section{Shahnai Basharat}

Assistant Professor

University Institute of Diet \& Nutritional Sciences

The University of Lahore, Punjab-Pakistan.

\section{Syed Amir Gilani}

Professor, Faculty of Allied Health Sciences

The University of Lahore, Punjab-Pakistan.

\section{Muhammad Mustafa Qamar}

(Corresponding Author)

Assistant Professor

Department of Allied Health Sciences

Sargodha Medical College

University of Sargodha, Punjab-Pakistan.

Email: dearqamar@hotmail.com

\section{Muhammad Ali}

Assistant Professor

Lahore University of Management Sciences, Lahore,

Punjab-Pakistan.

\section{Benazir Basharat}

Research Assistant, Kansas University, Kansas

United States of America.

\section{Mian Anjum Murtaza}

Associate Professor, Department of Food Sciences University of Sargodha, Punjab-Pakistan. 